\title{
ANÁLISE
}

\section{A GEOPOLÍTICA SIMBÓLICA DA SÍFILIS: UM ENSAIO DE ANTROPOLOGIA HISTÓRICA}

\author{
THE SYMBOLIC GEOPOLITICS \\ OF SYPHILIS: AN ESSAY IN \\ HISTORICAL ANTHROPOLOGY
}

Sérgio Carrara*

CARRARA, S.: 'The symbolic geopolitics of syphilis: an essay in historical anthropology'. Historia, Ciências, Satide - Manguinhos, III (3):391-408, Nov. 1996-Feb. 1997.

The article analyzes certain scientific ideas that Brazilian physicians, and particularly syphilologists, bave held about this disease. During the 1920's especially, these specialists constmicted a uniquely Brazilian version of the disease as they debated with foreign specialists on the origins, symptoms, and incidence of syphilis in Brazil. In their formulations, syphilis became a kind of natural symbol through which they expressed their desires to play a leading role within the international scientific community and put forth efforts to earn Brazil a new status in the world ranking of nations contesting the notion that Brazil was forever doomed to backwardness and barbarism because it was a tropical country with a racially mixed population.

KEYWORDS: medical anthropology, bistory of medicine, sexuality, nationalism, syphilis.

"Todos nós herdamos no sangue lusitano uma boa dosagem de lirismo. Além da sífilis, é claro."

Calabar, Chico Buarque e Ruy Guerra

- Doutor em antropologia, pesquisador e professor do Instituto de Medicina Social, da Universidade do Estado do Rio de Janeiro (IMS/UERJ). Rua São Francisco Xavier, $524 / 7^{\circ}$ bl. D, 20550-013 Rio de Janeiro - RJ
No contexto das sociedades ocidentais, poucas doenças oferecem tantas questões interessantes à reflexão histórica e sócio-antropológica quanto a sífilis. Problemas de toda ordem emergem quando nos debruçamos sobre a vastíssima produção erudita por ela motivada desde a sua irrupção na Europa em finais do século XV. Em sua realịclade quase totêmica, a sífilis tem sido "boa para pensar" sobre o modo pelo qual se produzem as "descobertas científicas"; ${ }^{1}$ sobre 
${ }^{1} \mathrm{E}$ interessante notar que as modernas análises sócio-antropológicas sobre o cliscurso e as práticas científicas têm como precursor justamente um trabalho sobre sífilis. Trata-se do livro de Fleck (1986), cujas idéias se desenvolvem a partir da análise da 'descoberta' de Wassermann, na Alemanha, em 1906, de um teste sorológico que possibilitava detectar a presença do Treponema palidum, considerado o agente causador da sífilis, no sangue dos contaminados.

${ }^{2}$ Algumas dessas questões têm sido exploradas por historiadores e cientistas sociais, como Brandt (1985); Quétel (1986) e Corbin (1988; 1982; 1981; 1977). as relações entre técnicas diagnósticas ou terapêuticas e nosologia; sobre os compromissos possíveis entre o pensamento científico e determinados imperativos morais e categorizações sociais; sobre as implicações éticas de certas intervenções cientificamente orientadas; sobre a divisão internacional do trabalho científico etc. ${ }^{2}$

Os domínios da sífilis são realmente imensos, mas não quero com isso perpetuar aqui uma idéia que os especialistas em sífilis, os sifilógrafos, souberam muito bem impor desde finais do século XIX, ou seja, de que a sífilis era uma espécie de "doença total", atacando todos os órgãos, todas as raças, em todas as idades e indivíduos de qualquer sexo. Ao contrário, este artigo aborda um tema bem específico, desenvolvido mais longamente em um outro trabalho (Carrara, 1996). Trata do modo pelo qual, durante o período que se estende de finais do século passado até meados da década de 1940, os sifilógrafos brasileiros estabeleceram as particularidades da doença no Brasil. Como, através dela, pôde-se pensar a posição do país no concerto das nações e se pretendeu, principalmente a partir da década de 1920 , re-situá-lo, reivindicando seu acesso ao mundo dito então 'civilizado'. Para tanto, acompanharei resumidamente o diálogo nem sempre explícito que os médicos brasileiros, especialmente os sifilógrafos, mantiveram com seus colegas estrangeiros.

Ao longo de todo o período histórico aqui considerado, é possível estruturar tal diálogo em torno de três temas principais. O primeiro relaciona-se à idéia de a sífilis ter se originado no continente americano, devendo, portanto, ser considerada doença autóctone no país. O segundo diz respeito à sua enorme disseminação no Brasil, comparativamente a outros países, dadas certas variáveis biológicas, sociais e morais especificamente brasileiras. Tais variáveis explicavam em parte, e este é o terceiro tema, a feição singularmente terrivel com a qual a sífilis supostamente se manifestava entre nós. Assim, conforme transparece na documentação brasileira analisada, do ponto de vista da sifilografia internacional do período, além de espécie de patrimônio imemorial, a sífilis brasileira devia ser considerada, dada sua larga disseminação, uma espécie de atributo dos brasileiros, nos quais ela se manifestaria de modo terrivelmente grave e mutilante.

Foi em relação a essa representação genérica que os médicos brasileiros se posicionaram e o modo como o fizeram constitui o assunto deste artigo. Enfatizarei sobretudo o papel decisivo que, a partir da década de 1920, a sífilis desempenhou no âmbito da alentada discussão em torno das causas da degeneração do povo brasileiro. Ao deslocar o tema da miscigenação racial - dos efeitos eugenicamente nocivos da conjunção de neolatinos, como os colonizadores portugueses, com raças ainda mais 'inferiores' para o da patologia sexual, abriu a possibilidade de se pensar uma 'redenção' mais rápida e segura para o país. 
3 Sempre considerada doença do "outro", do "estrangeiro", entre seus inúmeros nomes, a sífilis foi também conhecida como mal-americano, malcanadense, mal-céltico, mal-cle-nápoles ou malnapolitano, mal-doscristãos, mal-escocês, malfrancês, mal-germânico, mal-ilírico, mal-gálico, malpolaco, mal-turco, malportuguês. Ao que parece, até o século XIX, no Brasil utilizavam-se sobretudo as expressões mal-venéreo e mal-gálico, ou simplesmente gálico.

As teorias fisiológicas de Broussais e seus discípulos encontraram inúmeros adeptos no Brasil na primeira metade do século XIX. Ao incorporá-las, eles passaram a acreditar que a sífilis não era doença contagiosa, e sim produzida por uma irritação dos orgãos sexuais, que posteriormente espalhava-se pelo corpo. Na origem de tal irritação estariam a repetição do ato sexual ou sua realização em condições consideradas antihigiênicas, principalmente com mulheres menstruadas.

\section{Uma doença estrangeira}

Atualmente há um certo consenso quanto ao fato de a sífilis ter sido uma doença desconhecida no Velho Mundo até finais do século XV. Porém, sua origem geográfica continua causando polêmicas (MacNeill, 1970). De fato, nenhuma outra doença provocou tão acirradas disputas em relação ao seu local de origem quanto a sífilis. Por ter sido uma das mais estigmatizantes doenças humanas, nenhum povo ou nação aceitava de bom grado ser apontado como seu berço, 'privilégio' que sempre se reservava aos inimigos. ${ }^{3}$ Como dizia um sifilógrafo brasileiro da década de 1920 (Almeida, 1925, p. iii): "A sífilis ninguém a quer, nem como hóspede, nem como vizinha e muito menos como patrimônio histórico ou de família. A sua vida de indesejável, negada por toda a parte, apresenta, já por si, um embaraço para a fixação de sua história através dos séculos."

Antes de ter se estabelecido mais firmemente ao longo da primeira metade do século $\mathrm{XX}$, a crença na origem americana do mal, que clandestinamente voltara à Europa nas naus de Colombo, parece ter oscilado conforme se aceitasse uma ou outra das diferentes concepções da doença. Caso se acreditasse, como faziam muitos, em sua geração quase espontânea a partir de uma sexualidade pecaminosa e/ou excessiva, a hipótese de uma origem americana não podia facilmente ser sustentada. Como o pecado havia nascido com o mundo e o excesso sexual não era uma prerrogativa dos índios americanos, não havia qualquer razão plausível para se acreditar que os antigos desconhecessem os seus frutos. Como explicitava um médico brasileiro (Lima, 1849, p. 2) de meados do século XIX:

"Se a natureza pretendeu castigar aqueles que infringiam as suas leis com as afecções sifilíticas, por sem dúvida não esperaria até o descobrimento da América para sobre os delinqüentes arremessar - golpe fatal, por isso que muitos séculos antes desse descobrimento viveram os césares, os neros, os heliogábalos, as messalinas e outros prodígios de voluptuosidade."

Até a passagem do século, mesmo depois de a relação entre a sífilis e a imoralidade ter se tornado indireta e mediada pelo contágio, o valor moral da doença continuou a fornecer argumentos aos que se opunham à chamada hipótese americana. Assim, se muitos ainda duvidavam da origem americana da sífilis, era porque, como dizia um outro médico brasileiro (Pires de Almeida, 1902, p. 77), "as Américas não ofereceram nunca os mais obscenos exemplos de corrupção que nos apresentou o Velho Mundo".

A hipótese americana estava igualmente excluída caso se considerasse a doença como transformação de outra doença mais antiga, como a lepra, como produto de conjunções astrológicas ouclimáticas, ou, ainda, como simples fenômeno inflamatório. ${ }^{4}$ Desse 
5 É o caso do médico francês radicado no Rio de Janeiro, José Francisco Xavier Sigaud, que defendeu a hipótese americana em seu $D u$ climat e des maladies du Brésil. Segundo o mais importante historiador da medicina brasileira, este trabalho deve ser considerado "o melhor e mais substancioso tratado escrito no século passado sobre o estado da medicina no país" (Santos Filho, 1991, p. 15). modo, embora nem todos os contagionistas fossem partidários da hipótese americana, todos os que defendiam a origem americana do mal supunham necessariamente seu caráter contagioso. Pode-se mesmo acreditar que, depois da 'revolução pasteuriana', com a vitória indiscutível dos contagionistas, a consolidação da hipótese americana tenha recebido contribuição decisiva.

Durante o século XTX, a opinião dos médicos brasileiros a esse respeito parece ter divergido bastante. Enquanto figuras eminentes acreditavam ser a sífilis doença autóctone no continente, ${ }^{5}$ outros já apontavam claramente o caráter discriminatório e estigmatizante da hipótese americana. Para alguns, os europeus, mais particularmente os espanhóis, querendo desculpar o seu "procedimento com os desgraçados americanos" fizeram "acreditar ao povo e mesmo a um avultado número de facultativos ilustres que a pura, a inocente América, ignorando torpezas, ornada dos costumes os mais simples, havia comunicado Sífilis à já tão corrupta e voluptuosa Europa" (Lima, 1849, p. 2).

Com a progressiva aceitação da origem americana do mal, ao longo da primeira metade do século XX, a comunidade de sifilógrafos brasileiros, cada vez mais numerosa e poderosa, irá empreender um importante trabalho de geopolítica simbólica: demonstrar que, sendo de origem americana - como acreditavam, entre outros, grandes especialistas europeus, como os franceses A. Fournier e E. Jeanselme - a sífilis não era, entretanto, conhecida no Brasil antes do descobrimento. Ou, como em 1918 dizia o mais importante sifilógrafo brasileiro do período, o prof. Eduardo Rabelo (1921, p. 325), que ela havia sido "mau grado nosso, implantada em nosso solo virgem e transmitida à nossa raça sadia". Para Rabelo, não parecia haver dúvida quanto ao fato de a sífilis ser originária das Grandes Antilhas e de ter sido levada à Europa por Colombo, como queriam então os mestres franceses. Em artigo de 1925, ele dizia:

"Assim depõem, para bem dizer, todos os escritores da época; cronistas, historiógrafos, amigos ou inimigos dos índios e, principalmente, os médicos que, a partir da data da volta de Colombo, começaram a descrever com impressionante unanimidade o 'morbus novus', 'inauditus', 'ignotus' que, passando da América à Espanha, assolou a França e a Itália sob aspecto francamente epidêmico, tal como ainda hoje vemos a sífilis se propagar em certas possessões européias de além-mar, ainda indenes. Tanto era desconhecida que lhe não sabiam o nome e foi sendo mal espanhol, francês, napolitano, até que do poema de Fracastor se derivou a atual denominação."

Porém, não podia ser brasileira. E, para prová-lo, o sifilógrafo se volta para os cronistas do século XVI e para os testemunhos sobre os povos indígenas brasileiros ainda isolados, que começavam então 
6 A identidade entre bouba e sífilis levantaria ásperas discussões no meio médico brasileiro da passagem do século XIX para o XX. Ao que parece, a polêmica só terminaria definitivamente depois de 1905, ano em que Castelani 'identificou' 0 suposto agente causador da bouba ou framboesia trópica, também conhecicla como pian ou yaws. Tratava-se de un outro treponema (Treponema perlenue), morfologicamente idêntico ao da sifilis e que, embora cedesse também à ação do mercúrio, não era de transmissão sexual. A bouba era encontrada sobretudo nas zonas tropicais das Américas, África, Sucleste da Ásia e Oceania (Bechelli, 1976, p. 809).

7 Segundo a antropóloga Nádia Farage (1991), o ouvidor-geral da Capitania do Rio Negro, Ribeiro de Sampaio, deixou relatos de duas viagens ao extremo Norte do país: uma realizada em 1775 ao rio Negro, e outra, ao rio Branco, em 1777. a ser produzidos de forma mais sistemática. Para ele, todos os nossos cronistas de primeira hora haviam tecido "universais gabos à pele dos índios". Apenas os cronistas da segunda metade do século XVI (André Thévet, Jean de Lery, Gabriel Soares de Souza) e observadores posteriores teriam se referido à incidência de males que se poderiam considerar manifestações sifilíticas ou boubáticas ${ }^{6}$ entre as populações indígenas, já em contato regular com europeus e africanos. Além disso, observadores contemporâneos que penetravam os sertões, como Rondon, Murilo de Campos, Olímpio da Fonseca Filho e Roquette-Pinto, atestavam que populações indígenas ainda isoladas eram indenes à sífilis.

Também na década de 1920 , a inexistência da sífilis no Brasil pré-cabralino começava a ser intensamente defendida por um outro importante sifilógrafo brasileiro, o carioca Oscar da Silva Araújo. Em longa e fundamentada exposição, ele retoma as fontes sobre as quais se baseavam os que até então mantinham opinião contrária (Araújo, 1928). O eminente prof. Sigaud, escrevendo em meados do século XIX, apoiava-se em relato setecentista do viajante português Ribeiro de Sampaio para defender a hipótese americana. ${ }^{7}$ Tal relato era sem dúvida estratégico, por tratar justamente da região do rio Negro, no Norte do país, mais próxima, portanto, das Antilhas. Citando Sampaio, Araújo mostra que os sintomas por ele descritos só teriam podido ser considerados sifilíticos por Sigaud devido ao fato de ainda não se ter distinguido a sífilis de outras dermatoses e doenças venéreas, em meados do século XIX. Assim, - mais provável parecia ter sido a introdução da sífilis apenas depois da chegada dos portugueses, quer fosse através dos novos contatos intra-americanos, ou, mais provavelmente, "de torna viagem", como dizia Rabelo, com os colonos europeus.

É certo que outros sifilógrafos do período, como Teófilo de Almeida, continuariam a defender in totum a origem não-americana da doença. Nesse ponto, como ironizava em 1925 (op. cit., p. 3), estava de acordo com os pesquisadores norte-americanos, que "renunciam essa reivindicação que se faz para América, de ser o berço da sífilis, inda mesmo que esse berço sejam as Antilhas...". De todo modo, difunde-se rapidamente no meio médico brasileiro a idéia de a sífilis ter sido trazida para o Brasil pelos europeus (especialmente pelos franceses e pelos degredados portugueses), ou seja, de que aqui, como afirmava Oscar da Silva Araújo, melhor do que em qualquer outro lugar do mundo, teria aplicação a máxima "civilização igual a sifilização".

Percorrendo a densa rede de relações que à época unia especialistas brasileiros e estrangeiros, essa idéia logo iria ser adotada fora do país. Em meados da década de 1920, ela seria reproduzida, por exemplo, pelo diretor da Sociedade Alemã de Luta contra as Doenças Venéreas, H. Roeschmann, em seu trabalho comparativo 
sobre a luta antivenérea em diferentes países. Ao discorrer sobre o Brasil, ele afirmava (1929, p. 37):

"No que respeita à origem da sífilis a opinião mais aceita é que tenha sido ela trazida da América do Norte para a Europa na armada de Colombo; para a América do Sul ela foi levada pelos portugueses, ocasião em que houve disseminação entre os habitantes que entraram em contato com os colonizadores, sobretudo entre as populações litorâneas. Os habitantes do interior ficaram por longo tempo completamente indenes."

Como se vê, durante a década de 1920, a reflexão sifilográfica brasileira conseguiu a extraordinária façanha de fazer com que a sífilis pudesse ser simultaneamente americana, como queriam os mestres europeus, e européia, como queriam os americanos. Interessante origem da doença que simbolicamente parece traduzir; de um lado, a própria posição que os sifilógrafos brasileiros (e mais amplamente, a medicina brasileira) assumiam na hierarquia internacional de especialistas: dependentes, é certo, dos centros europeus, mas já com poder suficiente para desenvolverem uma reflexão científica original. De outro lado, parecia também traduzir a própria posição que se reivindicava para o Brasil na hierarquia das nações. Ora, seguramente havia países ainda mais pobres e politicamente mais frágeis, como os das Antilhas, para carregarem sem protestos o ônus de serem o berço do mal. Nesse sentido, a reflexão dos sifilógrafos brasileiros quanto à origem da sífilis não deixava de distinguir o Brasil dessas outras nações, incorporandoo, ainda que parcialmente, ao "mundo civilizado".

Movimento semelhante transparece, como veremos a seguir, também quanto ao outro ponto de discordância entre os médicos brasileiros e seus colegas europeus e que dizia respeito à icléia da extrema malignidade com que a sífilis se manifestava nos trópicos.

\section{Uma sifilis mais benigna}

Em finais do século XIX, acreditava-se que a doença se manifestava de forma muito mais grave nos climas quentes, constituindo-se em tipo específico chamado de sífilis exótica ou tropical. Conforme se dizia no Brasil, no início da década de 1920, apoiando-se na hipótese climática: "Lacapère, entre outros, encontrou grandes diferenças sintomáticas entre a sífilis dos europeus e a dos marroquinos. Nestes, as lesões cutâneas e ósseas, de extrema severidade, predominam sobre as lesões visuais e nervosas" (Gurjão, 1922, p. 299).

Ao longo das primeiras décadas do século XX, ao mesmo tempo em que se adensava a rede de especialistas brasileiros, a crença na malignidade da sifilis tropical era progressivamente desfeita. Esse 
processo parece ter ocorrido, sobretudo, através da diferenciação entre diversas entidades mórbidas que apresentavam sintomas semelhantes. Inicialmente, diferenciou-se a sífilis da bouba. Depois, com a significativa contribuição de pesquisas médicas realizadas no Brasil, outras diferenciações se seguiram, fazendo com que os médicos passassem a distinguir a sífilis de outras doenças tropicais com manifestações cutâneas. Como diz Rabelo (1925, p. iii): "Quando ainda se confundiam com a sífilis, a leishmaniose, o granuloma tropical e a úlcera fagedênica, supunha-se que a sífilis era mais grave em nosso clima do que em outras regiões."

Araújo (1928, p. 69) reafirmava a idéia de o "mito" da malignidade da sífilis no Brasil se explicar em larga medida por "erros" de diagnóstico: "Notara-se a existência entre nós de doentes rotulados de sifilíticos que exibiam manifestações mutilantes. Hoje se sabe que não se tratava ali de casos graves de sífilis atípica, mas de enfermos acometidos de leishmaniose, de blastomicose, de granuloma venéreo etc."

Referindo-se especificamente ao Rio de Janeiro, Araújo (op. cit., p. 28) dizia que, embora a freqüência da sífilis atingisse "proporções impressionantes", suas manifestações clínicas não diferiam, fundamentalmente, da sífilis européia, "não sendo a sua evolução mais grave do que a de ordinário em outros países de clima frio ou temperado". Para o referido autor, se a sífilis às vezes assumia manifestações mutilantes no país (principalmente em certas regiões do Nordeste), isso se explicava pelo fato de atingir eventualmente populações menos miscigenadas $e$, por isso mesmo, até então menos expostas à doença. Ao afetá-las, a sifilis assumiria as mesmas características terríveis que teria apresentado quando irrompeu na Europa em finais do século XV.

Enfim, ao longo das décadas de 1920 e 1930, apoiando-se em estatísticas mais seguras, os sifilógrafos começavam a confirmar que as características da sífilis no Brasil não só diferiam do modelo tropical ou maligno, construído a partir da observação de casos africanos, mas no geral apresentavam-se muito mais benignas que as da própria sífilis européia. Embasado em extensas estatísticas, o sifilógrafo Henrique de Moura Costa (1938, p. 129) era contundente: "Existem notáveis diferenças entre o que se observa entre nós e as descrições dos tratadistas europeus. Também o que entre nós se observa não pode ser comparado ao que descrevem os autores que estudaram a chamada sifilis tropical ou exótica."

Ao que parece, em matéria de sífilis, como em outros tantos assuntos, o Brasil conseguia, lentamente, se colocar a meio caminho entre África e Europa... E o importante aqui talvez seja perceber que não poderia ter construído uma sífilis "particular" — a um só tempo estrangeira e benigna -, caso não dispusesse de bons sifilógrafospesquisadores interessados nesta particularização. Do mesmo modo, 
não haveria bons sifilógrafos sem que houvesse uma certa tradição sifilográfica e científica, assim como as condições materiais e institucionais mínimas que lhes assegurassem certa vitalidade. Na década de 1920, nada disso parecia faltar ao Brasil, ao menos em seus principais centros urbanos.

\section{"Pois há brasileiro que não seja sifilítico?"}

Conforme dizia Araújo (1928, p. 11), a grande incidência da sífilis no Brasil, especialmente no Rio de Janeiro, vinha sendo apontada por fontes mais seguras desde o século XVIII. Além de citar cronistas que falavam igualmente da "dissolução dos costumes" e da incidência do mal venéreo, Araújo afirmava que, em 1798, o Senado da Câmara do Rio de Janeiro teria organizado um inquérito para apurar quais as doenças endêmicas e epidêmicas mais comuns na cidade. Três médicos ali radicados teriam respondido a tal inquérito, sendo que dois deles assinalavam a freqüência das doenças venéreas. Através clos trechos citados por Araújo (op. cit., p. 12), pode-se perceber com clareza como a constatação dessa freqüência articulava-se diretamente às avaliações sobre a imoralidade reinante. Segundo dizia, por exemplo, um dos médicos consultados:

"As causas morais e dietéticas influem assaz para as moléstias do país. Os antigos afirmam que as tísicas, hoje tão freqüentes no Rio de Janeiro, raríssimas vezes se observavam, assim como as doenças da pele. Ora, se nós cavarmos mais fundo, acharemos que quase todas são complicadas com o vício venéreo. A opulência desta respeitável cidade faz introduzir o luxo e a depravação dos costumes, de maneira que dentro da cidade não faltam casas públicas, onde a mocidade vai estragar a sua saúde e corromper os costumes de uma boa educação, contraindo novas enfermidades e dando causas para outras tantas."

O outro médico a se pronunciar sobre o assunto lançava mão de um raciocínio que, sob feições diferentes, perduraria até meados do século XX. Dizia ser na escravidão que se devia procurar a origem da devassidão reinante, pois a prostituição seria a "conseqüência indefectível do ócio e da riqueza adquirida sem trabalho e fomentada pelo exemplo familiar dos escravos, que quase não conhecem outra lei que os estímulos da natureza" (idem, ibidem).

Já em meados do século XIX, em seu tratado sobre o clima e as moléstias do Brasil, Sigaud afirmava que "a sífilis existiu em todas as épocas no país e é hoje doença predominante" (idem, ibidem, p. 17). À mesma época, a doença começava também a ser responsabilizada pela "velhice prematura", que, segundo alguns, caracterizava a mocidade brasileira (Azambuja, 1847, p. 3). Testemunho 
${ }^{8}$ Em parte, talvez, devido à intensidade da clisseminação do mal nas tropas durante a guerra do Paraguai ou por sua maior valorização por parte dos médicos militares. da crescente preocupação que assumia ao longo da década de 1860 , a sífilis começava a figurar em diversos relatórios anuais de inspetores de saúde provinciais como a moléstia que, ao lado da tuberculose, das alterações intestinais e das febres intermitentes,"mais estragos fazem à população menos abastada" do Império - assim dizia então um inspetor de saúde da Bahia (idem). Começava-se também a revelar numericamente o peso de sua contribuição no total de internamentos em diferentes hospitais. Em artigo publicado na Gazeta Médica da Babia, dizia-se que, para "se conhecer a extensão que desgraçadamente vai ganhando o elemento sifilítico entre nós", bastaria olhar as estatísticas dos hospitais, pois, no período de 1861 a 1866 , mais de um terço dos doentes internados nas enfermarias de cirurgia da Santa Casa da Misericórdia do Rio de Janeiro seria de portadores de doenças venéreas (Anônimo, 1871, p. 26). Segundo o mesmo artigo, a partir de tais dados "colige-se evidentemente a expansão que vai tomando a propagação das moléstias venéreas entre nós, e quanto, continuando a expandir-se em proporção equivalente por falta de aplicação de medidas tendentes a neutralizar suas funestas conseqüências, atingirá em breve grandiosas proporções".

Sob o impacto da guerra com o Paraguai (1865-70), alarme semelhante se fazia ouvir nos meios militares. A partir da década de 1870 , a grande incidência da sífilis e das outras doenças venéreas nas tropas começava também a ser enfatizada. ${ }^{8} \mathrm{Em}$ 1873, João José de Oliveira Junqueira, ministro da Guerra do Império, destacava as doenças venéreas como a afecção mais comum entre os soldados, seguida numericamente pelas doenças do "aparelho respiratório e de digestão" (Araújo, 1928, p. 24). Para o período 1872-73, o médico José de Góes Siqueira Filho calculava que um terço das tropas aquarteladas na Corte estaria contaminado (idem). Dez anos depois, em 1883, através de uma memória apresentada à Academia Imperial de Medicina, o médicomilitar José de Oliveira (idem, p. 23) seria ainda mais contundente:

"Se a tuberculose representa no Exército brasileiro a maior cifra mortuária, se os embaraços gástricos não lhe cedem o passo na questão numérica, as moléstias venéreas e sifilíticas avantajam-se às duas. Pode-se, sem medo de errar, asseverar que não há um só soldado nosso que não tenha uma ou mais entradas nos hospitais por acidentes venéreos. A cirurgia hospitalar do Exército é constituída em tempo de paz pelo sem-número de blenorragias, cancros venéreos e bubões. Os acidentes secundários e terciários de sífilis, exostoses e reumatismo contam-se por centenas."

A partir da segunda metade do século XIX, os médicos não denunciavam apenas a grave situação do Rio de Janeiro. $O$ prof. Claudemiro Caldas (1866, p. 89) escrevia na Gazeta Médica da Babia 
9 O médico chegava a esta aterradora constatação a partir do número estimado de prostitutas residentes na cidade $\mathrm{e}$ do número de relações sexuais potencialmente contaminadoras que elas manteriam por ano. que, "no quadro nosológico da clínica cirúrgica da Faculdade da Bahia, avulta, pelo maior número de vítimas, a sífilis". E, em finais do século, o conhecido psiquiatra Juliano Moreira (1899, p. 113) ressaltava já haver dito por diversas vezes que "a sífilis na Bahia é de uma freqüência notável", acrescentando que, no Brasil, "de dia em dia amplia o terrível mal o seu domínio". O mal estaria também firmemente instalado na cidade de São Paulo, onde, segundo os estranhos cálculos apresentados por um médico paulista no início do século XX (Souza, 1909, p. 7), haveria uma média de trinta mil contaminações sifilíticas por ano, o que significava dizer que, a cada ano, $10 \%$ de seus habitantes se contaminavam. ${ }^{9}$

Assim, frente a estatísticas bastante precárias, quase inexistentes, os médicos da passagem do século ancoravam suas denúncias sobretudo em sua experiência clínica e nos dados fornecidos pela população hospitalizada. É verdade que, ao avaliarem a extensão da doença no Brasil, alguns deles também se apoiavam no senso comum, para o qual, como revelava explicitamente Juliano Moreira (1899, p. 113), o Brasil parecia ser a morada ideal da sífilis. Segundo o ilustre médico baiano, era comum se dizer "em família", frente a qualquer afecção: "isto é gálico". Tanto o vulgo quanto os médicos tinham a tendência, segundo dizia, a exagerar o "círculo do qualificativo", "batizando" de sífilis "a mais banal das dermatoses parasitárias, o mais trivial dos acnes, a mais genuína blefarite, a mais simples das conjuntivites". Segundo relatava, era "comum" se ouvir dizer: "Pois há brasileiro que não tenha a sua tara sifilítica?" Para o referido autor, "descontando o exagero", bem se via aí "a fórmula indicadora da disseminação do mal".

Diferentemente do que acontecia em relação à hipótese americana do mal e a de sua malignidade nos trópicos, e apesar do papel fundamental que tiveram na diferenciação entre a sífilis e certas doenças tropicais presentes no país, os sifilógrafos brasileiros da primeira metade do século XX iriam, entretanto, perpetuar a idéia da disseminação da sífilis ser particularmente assustadora no país, cujo estatuto já era então o de "verdade tradicional". Como até a década de 1940 a sífilis não era doença de notificação compulsória, nem havia uma padronização diagnóstica unanimemente aceita, toda espécie de especulação estatística foi possível. E sempre no sentido de sustentar tal "verdade". Além disso, o próprio caráter proteiforme da doença (suas múltiplas manifestações sintomáticas) propiciava enormes divergências quando se tratava de saber quais seriam os critérios ideais para definir uma determinada manifestação patológica como sífilis. Alguns utilizavam um critério clínico e incluíam na rubrica sífilis uma enorme diversidade de doenças e de anomalias congênitas ou hereditárias. Outros pautavam-se apenas nos resultados dos exames de sangue que, além de não serem confiáveis pelos critérios atuais, ainda permitiam interpretações, pois, ao menos quando 
${ }^{10} \mathrm{Em}$ sua recente história sobre o teste de Wassermann, Löwy (1993, pp. 19-20) afirma que "um teste positivo era considerado - principalmente no período inicial de entusiasmo pelo novo método como prova infalível da infeç̧̃̃o treponêmica e não como um elemento que contribuiria para 0 diagnóstico". Depois da Segunda Guerra Mundial, ao surgirem testes que possibilitavam a detecção do próprio treponema na corrente sanguínea, verificou-se que o teste de Wassermann produzia resultados positivos também em face a inúmeras outras doencas e que, para certas populações, o número de falsos positivos podia ser assombroso. Desse modo, conclui a mesma autora: "milhares de pessoas que hoje seriam consideradas falsos positivos foram diagnosticadas como portadoras da sífilis. Sofreram não apenas as conseqüências sociais e psicologicas de tal diagnóstico - medo, culpa, vergonha e condenação social -, mas, também, os efeitos bastante tóxicos do tratamento anti-sifilítico que era, então, preconizado.

11 Para justificar tal afirmação quanto aos "civilizados", Kehl oferecia contraditoriamente estimativas bastante superiores. Citando Fournier, dizia que, na França, haveria de $13 \%$ a $16 \%$ de adultos atingidos pela sífilis. Para a Alemanha, Blaschko (1906) teria calculado $18 \%$ na "classe burguesa". E, para os Estados Unidos, Day e McNitt teriam estimado uma incidência de $6 \%$ a $13 \%$ das "classes burguesas", $20 \%$ entre os "pobres brancos" e $30 \%$ entre os se tratava do tradicional teste de Wassermann, apresentavam-se em um contínuo do "fortemente positivo" ao "fortemente negativo". ${ }^{10}$

Enfim, não se trata aqui, obviamente, de tentar chegar a nenhuma verdade sobre a extensão da sífilis no Brasil. Apesar de toda a sua incongruência, os números sempre desenhavam os limites (in)variáveis da percepção generalizada de que o Brasil era a morada ideal da sífilis. Sempre presente no discurso sifilográfico, a equação "brasileiro = sifilítico" justificava até mesmo que as estatísticas fossem em certos momentos consideradas dispensáveis ou desnecessárias, quando se tratava de determinar a real incidência da doença no Brasil. Assim, por exemplo, dizia um médico no início do século XX (Souza, 1909, p. 6) que "sobre a sífilis e as moléstias venéreas, quase não há necessidade de estatísticas no Brasil, podendo-se contar o número de vítimas, aproximadamente, pelo número de brasileiros. É uma exageração? De modo algum."

No âmbito do $1^{\circ}$ Congresso Sul-Americano de Dermatologia e Sifilografia, realizado no Rio de Janeiro em 1918, o clínico Oscar Clark (1921, p. 188) abria sua comunicação afirmando que "a freqüência da lues no Brasil é do domínio histórico e até viajantes estrangeiros que percorrem o nosso país levam a impressão de que todo o nacional seja sifilítico".

Foi essa situação supostamente terrivel que embasou, até a década de 1920, o clamor dos médicos por medidas de combate à doença e suas críticas ao imobilismo dos diferentes governos republicanos. Com o início da primeira campanha nacional de combate à sífilis, depois de 1921, atenua-se significativamente o alarme estatístico. Entre as medidas então adotadas contra a sífilis não figurava, entretanto, sua notificação obrigatória, permitindo que médicos e sifilógrafos continuassem operando com dados bastante imprecisos. A estimativa que se estabeleceu durante a década de 1920 apontava para um índice de contaminação da população brasileira em torno de um quinto. Considerado extremamente alto, ele prevaleceria inalterado até o início da década de 1940. Já em 1921, na primeira palestra educativa promovida pela então recém-criada Inspetoria de Profilaxia da Lepra e das Doenças Venéreas, o eugenista Renato Kehl iria utilizá-lo. Depois de dizer que, não sendo doença de notificação obrigatória, seria impossível qualquer estatística segura, ele estimava, apoiado na autoridade dos sifilógrafos, especialmente em Eduardo Rabelo, existirem no Brasil seis milhões de sifilíticos, ou seja, $20 \%$ de sua população. Já o número de gonorréicos seria, "sem exagero no cálculo", um pouco menor, quatro milhões e oitocentos mil, perfazendo $16 \%$ da população. Em contraste, segundo o eugenista, nos "países civilizados", essas taxas seriam bem menores e a sífilis atingiria apenas $10 \%$ da população." $\mathrm{A}$ isso, acrescentava (Kehl, 1921, pp. 38-9): "Podereis vós, que nos ouvis, suspeitar que estamos enegrecendo o quadro mórbido do Brasil. Mas afirmamos escudados 
"negros pobres" (Kehl, 1921, p. 33). Quanto ao número de casos de gonorréia, dizia Kehl que, nos Estados Unidos e Alemanha, estimava-se que $80 \%$ dos homens adultos, antes de completarem trinta anos, já a teriam adquirido, e que de $70 \%$ a $95 \%$ das prostitutas tinham estado ou estavam doentes. No Brasil, acrescentava, na falta de uma propaganda contra a prostituição e da divulgação dos meios profiláticos, os números da gonorréia deveriam alcançar de $70 \%$ a $90 \%$ da população adulta masculina e $100 \%$ entre as prostitutas. No Rio, segundo diz, $90 \%$ dos homens adultos teriam ou já teriam tido gonorréia (op. cit., pp. 46-7).

12 Até meados do século $\mathrm{XX}$, autores tão díspares quanto Paulo Prado, Nina Rodrigues, Gilberto Freyre ou Afonso Arinos de Melo Franco apontariam a sensualidade ou a lubricidade como traço distintivo do caráter nacional brasileiro, ou, ao menos, como uma de suas características importantes (Leite, 1983; Parker, 1991). Se, como diz a historiadora Laura de Melo e Souza (1993), o Brasil nasceu sob o signo do demônio, terra do pecado, só podia ser também a terra da sífilis. na opinião de cientistas de valor e probidade indiscutiveis, que infelizmente essa é a verdade."

Em 1934, com a suspensão da campanha antivenérea iniciada na década anterior, o alarme estatístico voltaria a crescer progressivamente e o Brasil continuaria a manter seu estatuto de país particularmente 'sifilizado'. É o que evidenciam, por exemplo, as afirmações do médico da armada portuguesa Emílio Faro (1934, p. 184), em artigo publicado no Jornal de Sifilis e Urologia. Depois de dizer que uma grande parte da população portuguesa estava contaminada e que os europeus acreditam que quase todos os portugueses eram sifilíticos, complementava: "Nós portugueses fomos muito atingidos. Antigamente, pelas grandes viagens que fizemos, tanto para o Oriente, quanto para a América do Sul; nos últimos tempos, pela nossa grande emigração para o Brasil. Ali, a sífilis é tão freqüente que, entre nós, pode dizer-se que quem viveu algum tempo nesse país é sifilítico com certeza."

Em 1940, no âmbito da $1^{\text {a }}$ Conferência Nacional de Defesa contra a Sífilis, promovida sob o governo ditatorial de Getúlio Vargas, os especialistas fazem um novo esforço de avaliação numérica da extensão da doença, concluindo que o mal permanecia bem instalado no país e que, resistindo aos esforços para debelálo, podia continuar a ser considerado um dos fatores decisivos para a degeneração da raça brasileira.

\section{Luxúria, raça e patologia}

Não me parece haver dúvida de que a percepção do Brasil como país de sifilíticos era caudatária da idéia mais geral de que os brasileiros se caracterizariam por ser excessivos sexualmente. ${ }^{12}$ Até as três primeiras décadas do século XX, uma conjunção singular de fatores climáticos e raciais vinha sustentar fortemente o mito da luxúria do brasileiro. Desde pelo menos o início do século XIX, sabia-se que o clima cálido favorecia a devassidão, por excitar mais cedo a puberdade. Além do clima, a raça também influenciaria o apetite sexual. O médico francês Julien Joseph Virey (1836, p. 54) não se esquecia dela quando afirmava sobre a incontinência sexual e seus perigos, que "todos os africanos da zona ardente parece que trazem nas veias o fogo da lubricidade". E, embora veladamente, era tal idéia que se escondia atrás da "constatação" de um médico brasileiro de que, no Haiti, "a lubricidade por tal forma enfraqueceu a espécie, que muitos núcleos daquelas terras acham-se hoje, ou despovoados, ou degenerados, pelo flagelo da sífilis" (Pires de Almeida, 1902, p. 20).

Ainda que em menor grau, mesmo os povos de raça latina, neolatinos como os portugueses, eram também conhecidos por seu ardor sexual. Como dizia o higienista brasileiro Afrânio Peixoto (1913, p. 99), a abstinência sexual é "prática de higiene e moral, tão 
13 Geralmente, o surgimento de cancros extragenitais (nos lábios, ânus, mãos etc.) indicava a prática de atos sexuais não convencionais, pois a fericla surgia no local em que o Treponema entrara no organismo. Como se julgava frequentemente que a procura dos "prazeres perversos", ou seja, a transgressão das normas sexuais fosse geralmente ocasionada pelo abuso dos atos sexuais normais e a conseqüente extenuação do prazer obtido através deles, concluía-se que a incidência dos cancros extragenitais seria um bom índice para se medir o excesso sexual de um indivíduo ou de um grupo social. infringida, que é quase ridícula sua observância entre os povos latinos". Assim, até a década de 1920, quando se tratava de explicar o excesso sexual que caracterizaria o brasileiro, determinando a enorme disseminação da sífilis no país, muitos médicos lançavam mão dessas hipóteses climáticas e raciológicas.

Porém, se a idéia de o brasileiro ser excessivo sexualmente estaria fadada a chegar mais ou menos intacta até nossos dias, os pressupostos que a sustentavam, principalmente os que diziam respeito às influências raciais, seriam questionados sobretudo a partir da década de 1920. Durante a mesma década, por exemplo, o sifilógrafo Oscar da Silva Araújo dizia que vários autores norte-americanos continuavam a acreditar que a sífilis era muito mais freqüente entre os negros, dada a precocidade da sua vida sexual. E, no Brasil, o sifilógrafo baiano Egas Moniz de Aragão teria mesmo utilizado, como critério para provar a "lubricidade simiesca sem limites" dos negros brasileiros, conforme qualificava, a grande incidência do cancro ex-tragenital entre eles. ${ }^{13}$ Oscar da Silva Araújo criticava veementemente as opiniões "exageradas" de Moniz de Aragão. Segundo ele, desde finais do século XIX, as estatísticas do Rio de Janeiro apontavam que a maioria dos cancros extragenitais se verificava justamente em indivíduos brancos, sobretudo portugueses. Se havia, portanto, "hiperestésicos sexuais", eles teriam vindo da população branca ou quase branca do Hemisfério Norte, que, como vimos, no mesmo momento passava também a ser considerada a verdadeira introdutora da infecção sifilítica no Brasil.

Embora apareça esporadicamente até a década de 1940, a hipótese climática também passa a ser alvo de crítica na década de 1920. Em 1922, por exemplo, um editorial da Folba Médica (ano III, $\mathrm{n}^{\mathbf{2}} 24,5.12 .1922$, p. 279) dedicado à educação sexual combatia tal hipótese. Conforme o editorialista, "se os raios de sol trazem mais calor, em compensação o metabolismo básico é menor". Portanto, a maior excitabilidade nervosa que poderia existir no Brasil começava a ser explicada sobretudo pela "falta de treno no domínio de si próprio", que caracterizaria o brasileiro, principalmente quando comparado ao anglo-saxão. Era, portanto, um problema de possível solução através de uma intervenção educativa e sanitária bem orientada. Assim, conforme o mesmo editorial, "Precisamos repudiar de uma vez por todas essa concepção desmoralizadora, segundo a qual estamos condenados a vegetar nas formas inferiores de civilização."

Efetivamente, a partir da décadá de 1920, os sifilógrafos brasileiros enfatizarão, sobretudo, a influência que fatores sócio-morais ignorância, pobreza, imoralidade do meio social, herança escravocrata etc. - teriam sobre a "necessidade sexual", produzindo os excessos. Condicionando a intensidade, constância e diversificação da demanda e da oferta no mercado sexual, tais fatores determinariam, 
14 Para Corbin (1977, p. 249), foi principalmente a partir dos trabalhos dos franceses Alfred Foumier e de seu filho, Edmond, que os médicos passaram a atribuir à sifilis "quase todas as má-formações, quase todas as monstruosidades", contribuindo para que a doença se tornasse antropologicamente relevante. Segundo o historiador francês, Fournier teria inaugurado "a idade de ouro da teratologia sifilítica".

${ }^{15}$ Embora essa tenha sido a tendência geral, deve-se notar, entretanto, que, nos dois principais centros de reflexão médica do país, ainda havia na década de 1920 divergências significativas quanto à importância atribuída à miscigenação racial como a fonte dos males que assolavam - país. Segundo a antropóloga Lilia $M$. Schwarcz (1993, p. 190), "Os médicos da Faculdade do Rio de Janeiro buscavam sua originalidade e identidade na descoberta de doenças tropicais. ... Já os médicos baianos farão o mesmo ao entender o cruzamento racial como o nosso grande mal, mas, ao mesmo tempo, nossa suprema diferença."

160 apelo em prol da salvação da raça através de uma luta antivenérea, lançado pelos sifilografos descle finais do século XIX, parece ter sido então mais firmemente incorporado por eugenistas como Renato Kehl; médicos-legistas e higienistas como Afrânio Peixoto, Leonídio Ribeiro, Rodrigues Dória; e psiquiatras como Antônio Austregésilo, Juliano Moreira, Heitor Carrilho etc. Assim, fundada por Gustavo Riedel no Rio de Janeiro, em 1923, a Liga Brasilei- em última instância, o ritmo de difusão da sífilis no país. E, o mais importante, diferentemente dos fatores biofisicos como raça e clima, elas podiam ser, através de uma intervenção esclarecida, alteradas mais rápida e facilmente, franqueando ao país o desenvolvimento em direção às tais "formas mais elevadas de civilização". Porém, mesmo acreditando progressivamente em uma possível "redenção", os sifilógrafos iriam manter fundamentalmente inquestionável o mito da hiperestesia sexual do brasileiro.

Se os sifilógrafos brasileiros tenderam a concordar com a imagem que seus mestres europeus faziam da extensa disseminação do mal venéreo entre nós, tal concordância trouxe, entretanto, certos ganhos secundários para o esforço que empreendiam no sentido de re-situar o país no concerto das nações. Ora, conjugadas à crença em sua extrema difusão, as características hereditárias então atribuídas à doença ${ }^{14}$ contribuíram significativamente para que a tradicional reflexão sobre a degeneração racial do povo brasileiro se deslocasse ao longo da década de 1920 do problema da miscigenação racial para o problema da patologia sexual. ${ }^{15} \mathrm{Se}$ os brasileiros eram degenerados, isso não se devia a qualquer fator constitucional, mas sim à doença, particularmente à sífilis, e em curto espaço de tempo esse quadro poderia ser revertido. ${ }^{16}$

Tal deslocamento parece ter encontrado sua versão mais radical e influente em Casa-grande e senzala do famoso sociólogo brasileiro Gilberto Freyre, que, publicado em 1933, pode ser considerada um testemunho inegável do grande impacto da reflexão sifilográfica da década de 1920 sobre o pensamento social que se produz a partir daí. Freyre faz inúmeras referências à sífilis nessa obra, apoiando-se amplamente nos trabalhos históricos de Oscar da Silva Araújo. Repetindo Araújo, Freyre (1954, p. 161) diz que o Brasil se "sifilizou" bem antes de se "civilizar" e que, entre as "influências sociais", "talvez sífilis tenha sido, depois da má nutrição, a mais deformadora da plástica e a mais depauperadora da energia econômica do mestiço brasileiro". Para ele:

“A vantagem da miscigenação correspondeu no Brasil a desvantagem tremenda da sifilização. Começaram juntas, uma a formar o brasileiro - talvez o tipo ideal do homem moderno para os trópicos, europeu com sangue negro ou índio a avivarlhe a energia; outra, a deformá-lo. Daí certa confusão de responsabilidades; atribuindo muitos à miscigenação o que tem sido obra principalmente da sifilização; responsabilizando-se a raça negra ou ameríndia ou mesmo a portuguesa, cada uma das quais, pura ou sem cruzamento, está cansada de produzir exemplares admiráveis de beleza e robustez física, pelo 'feio' e pelo 'bisonho' das nossas populações mestiças mais afetadas de sífilis ou mais roídas de verminose." 
ra de Higiene Mental teria o combate à sífilis como um dos principais meios para alcançar o seu objetivo maior: prevenir a incidência das doenças mentais no país (Costa, 1981). E, se Renato Kehl (1921, p. 7) entrara na luta antivenérea, era porque a sífilis "não só sacrifica a vítima, mas a descendência e, por prejudicial à raça, constitui um grande perigo nacional". Em 1929, as campanhas antivenéreas seriam um dos grandes temas discutidos no $1^{\circ}$ Congresso Brasileiro de Eugenia, realizado no Rio de Janeiro (Stepan, 1990, p. 119).

17 Depois de afirmar que, na primeira metade do século XX, o neolamarckismo era prevalente nos círculos médicos, Stepan (1990, p. 120) acrescenta: "Nessas décadas, a persistência entre os médicos de idéias lamarckianas cientificamente mais elaboradas refletia não sua estupidez ou ignorância, mas a aparente irredutibilidade de certos problemas da patologia humana. Tome-se, por exemplo, o impacto das doenças venéreas dos pais sobre a descendência: a 'adaptabilidade' clos filhos encontrava-se diminuída? E essa incapacidacle não era transmitida de forma hereditária? Havia uma condição hereditário-sifilítica? Esta era a opinião da maioria dos médicos na França, onde as idéias lamarckianas eram muito difundidas, informando o movimento eugenista que lá se desenvolvia."
A partir da década de 1920, e até o início da década de 1940, as concepções dos sifilógrafos parecem se adequar perfeitamente ao neolamarckismo que, diferentemente de países como os Estados Unidos e a Alemanha, teria marcado quase toda a reflexão brasileira sobre a hereditariedade nesse período. Como apontou a historiadora Nancy Stepan (1990), diferentemente dos países anglo-saxões, no Brasil e em outros países latinos, eugenizar significou predominantemente sanear. Para ela, isso se explica pelo fato de que, "influenciados" pelos teóricos franceses, os eugenistas, higienistas e médicos brasileiros em geral terem se pautado por idéias neolamarckianas, acreditando na hereditariedade dos caracteres adquiridos. Assim, a solução do "problema racial" no Brasil teria se centrado amplamente no combate às doenças epidêmicas e endêmicas que o assolavam e cuja nefasta influência, como permitia pensar o neolamarckismo, era sentida pela descendência, abastardando-a.

Através do neolamarckismo ressaltava-se que, se o Brasil era exemplo de país degenerado, isso não se devia nem ao clima nem à miscigenação, como defendiam Buckle, Gobineau e, desde o século $\mathrm{XIX}$, intelectuais brasileiros como Nina Rodrigues (Correa, 1982). Os brasileiros eram biologicamente inferiores, mas não se tratava de uma inferioridade inata, e sim de uma inferioridade conjuntural, situacional. No prazo de poucas gerações, caso se fizesse uma política sanitária e educativa bem dirigida, o Brasil podia ser eugenicamente redimido, purificado. As raças que compunham sua população exibiriam então seus atributos positivos, apenas momentaneamente mascarados pelas deletérias conseqüências de certas doenças como a sífilis, e de certos costumes perniciosos como o excesso sexual que a propiciava.

A consolidação da crença de que o "problema brasileiro" residia em larga medida na sífilis e não na mistura de raças contribuiu para instalar certo otimismo científico, que, segundo Stepan, desde a década de 1920 foi característico do esforço empreendido pelas elites nacionais para retirar do Brasil a condenação perene ao atraso e à barbárie, por ser mestiço e quente. Nesse contexto, a sífilis cuja importância para a sobrevivência das idéias neolamarckianas em todo o mundo foi apontada também por Stepan $-{ }^{17}$ teve, sem dúvida, um valor estratégico entre nós. Conjugadas à crença em sua extrema difusão no Brasil, devido ao excesso sexual que singularizava os nacionais, suas supostas características hereditárias contribuíram significativamente para que a luta contra a degeneração no país se realizasse principalmente através de intervenções sanitárias. Assim, ao invés de se eliminar ou esterilizar os biologicamente 'inaptos', como aconteceu em várias partes do mundo ocidental, buscou-se curar os males que os afligiam.

Consultando outras fontes referentes à história da medicina e da ciência no Brasil, a historiadora Nancy Stepan (1990, pp. 128-9) 
localiza justamente na década de 1920 a emergência de uma atitude que denomina "nacionalismo realista" e que levaria os brasileiros a"começar a rejeitar sua tradicional dependência em relação ao conhecimento e aos valores europeus, procurando novos caminhos para reinterpretarem sua condição social e climática. Assim, produziram para si mesmos uma visão mais otimista do país, coerente com a crença em suas imensas riquezas naturais e no caráter singular de seu perfil racial."

De fato, os sifilógrafos brasileiros contribuíram de modo significativo para a consolidação de um pensamento social de forte apelo nacionalista, que procurou valorizar o Brasil também pelo que possuía de não-europeu, deixando de atribuir as razões de todos os nossos males exclusivamente às heranças ameríndia e africana. Assim, no mesmo momento em que o ensaísta Paulo Prado (1931) escrevia que havíamos herdado a melancolia, a cobiça e a luxúria dos portugueses, os sifilógrafos acrescentavam: e a sífilis. Além disso, como se viu, suas manifestações sintomáticas no Brasil não deviam ser comparadas às da sífilis africana, assemelhando-se muito mais às da sífilis européia. Finalmente, se os médicos reforçavam a crença de o país ser particularmente sifilizado, isso não apenas consolidava o papel que eles próprios se atribuíam de salvadores da raça e da nacionalidade, mas também fazia com que suas intervenções sanitárias fossem vistas como adequadas e eficazes para atingir tal objetivo.

CARRARA, S.: 'A geopolítica simbólica da sífilis: um ensaio de antropologia histórica'. História, Ciências, Sauide - Manguinhos, III (3):391-408, nov. 1996-fev. 1997.

O presente artigo analisa certas idéias científicas que os médicos brasileiros, particularmente os especialistas em sífilis, ou sifilógrafos, desenvolveram a respeito da doença. Eles construíram, sobretudo ao longo da década de 1920, uma sífilis singularmente brasileira, discutindo com seus colegas estrangeiros a respeito da origem, das manifestações e da incidência da doença no país. Em suas formulações, a sífilis transformou-se em uma espécie de símbolo natural, através do qual expressavamse simultaneamente suas pretensões a uma posição de destaque na comunidade científica internacional e seu esforço em re-situar o país na hierarquia das nações, retirando-lhe o fado de, por ser quente e miscigenado, estar condenado para sempre ao atraso e à barbárie.

PALAVRAS-CHAVE: antropologia médica, história da medicina, sexualidade, nacionalismo, sífilis.

\section{REFERÊNCIAS BIBLIOGRÁFICAS}

Almeida, T. de ago. 1925

Anônimo 1871

Araújo, O. S. 1928
'Da origem não americana da syphilis'. Anais Bras. Dermat. Sifil., ano I, $\mathrm{n}^{\mathrm{Q}} 7$.

' $\mathrm{Da}$ frequencia das moléstias syphiliticas no Rio de Janeiro e da necessidade de adoptarem-se medidas que attenuem seus estragos'. Gazeta Médica da Babia, ano V, n 99 a 101.

Alguns commentários sobre a syphilis no Rio de Janeiro. Rio de Janeiro, Empreza Gráphica Editora Paulo Pongetti \& Cia. 
Azambuja, A. C. N. d' 1847

Bechelli, L. M. 1976

Brandt, A. M. 1985

Caldas, C. 1886

Carrara, S. 1996

Clark, $\mathrm{O}$.

Corbin, A. 1988

Corbin, A. 1982

Corbin, A. 1981

Corbin, A. dez. 1977

Correa, $\mathrm{M}$. 1982

Costa, H. M. 1938

Costa, J. F. 1981

Farage, $\mathrm{N}$. 1991

Faro, E. T. jun. 1934

Fleck, L. 1986

Freyre, G. 1952

Gurjão, H. 1922

Kehl, R.
Conselbos práticos sobre os meios de prevenir e curar immediatamente as moléstias venéreas, precedidos de noções geraes sobre a bistória, propagação, e modo de produçấo da sypbilis em linguagem adaptada à intelligência de todas as classes da sociedade. Paris, Typ. Fain e Thunot.

'Bouba'. Em R. Veronese, Doenças infecciosas e parasitárias. $6^{2}$ ed., Rio de Janeiro, Guanabara Koogan.

No magic bullet: a social bistory of venereal disease in the United States since 1880. Nova York/Oxford, Oxford University Press.

'Ligeiras considerações acerca das principaes theorias syphilográphicas'. Gazeta Médica da Babia, ano I, $\mathrm{n}^{\alpha i}$ 5 , 8, 14 e 18.

Tributo a Vênus: a luta contra a sifilis no Brasil, da passagem do século aos anos 40. Rio de Janeiro, Editora Fiocruz.

'Syphilis no Brasil e suas manifestações viscerais'. $2^{2}$ Boletim do VIII Congresso Brasileiro de Medicina, do $1^{\circ}$ Congresso Sul-Americano de Dermatologia e Sifilografia etc. Rio de Janeiro, Imp. Nacional.

'La grande peur de la syphilis'. Em Bardet; Bourdelais; Guillaume; Lebrune Quétel (orgs.), Peurs et terreurs face a la contagion - choléra, tuberculose et syphilis: $X I X^{\underline{e}}$ et $X X^{\underline{e}}$ siècles. Paris, Fayard.

Les filles de noces. Paris, Flammarion.

'L'hérédosyphilis ou l'impossible rédemption. Contribution à l'histoire de l'hérédité morbide'. Romantisme - Revrie du Dix-neuvième Siècle, nº 31.

'Le péril vénérien au debut du siècle: prophylaxie sanitaire et prophylaxie morale'. Recherches, $\mathrm{n}^{\circ} 29$.

As ilusôes da liberdade: a escola Nina Rodrigues e a antropologia no Brasil. Tese de doutouramento, São Paulo, USP/FFLCH.

'Aspectos e particularidades da sífilis no Brasil - parte especial'. Anais Bras. de Dermat. e Sifilog., ano XIII, $\mathrm{n}^{2} 34$.

História da psiquiatria no Brasil. $3^{\text {a }}$ ed. rev., Rio de Janeiro, Campus.

'As muralhas dos sertões: os povos indígenas no rio Branco e a colonização'. Rio de Janeiro, Paz e Terra/ANPOCS.

'Profilaxia das doenças venéreas na marinha de guerra portuguesa'. Jornal de Syphilis e Urologia, ano V, n 54.

La génesis y el desarrollo de un hecho científico - introducción a la teoria del estilo de pensamiento y del colectivo de pensamiento. Madri, Alianza Editorial.

Casa-grande e senzala: formação da familia brasileira sob o regime de economia patriarcal. Rio de Janeiro, José Olympio.

'A prostituição em Belém: suas causas, localização, fiscalização e assistência médico-sanitária'. Em H. C. de S. Araújo (org.), A prophylaxia nural no estado do Pará. Belém, Typ. da Liv. Gillet.

O perigo venéreo - conferência realizada no dia 25 de julbo de 1921, no salão da Associação dos Empregados do Commercio.

Rio de Janeiro, Dep. Nac. de Saúde Publ. e

Inspectoria de Prophylaxia da Lepra e das Doenças Venéreas. 
Leite, D. M. 1983

Lima, J. T. de 1849

Löwy, I. 1993

MacNeill, W. H. 1976

Moreira, J. jul. 1899

Parker, R. G. 1991

Peixoto, A. 1913

Pires de Almeida, J. R. 'A libertinagem no Rio de Janeiro perante a história, os costumes e a moral'. 1902

Prado, $\mathbf{P}$. 1931

Quétel, C. 1986

Rabelo, E. jan. 1925

Rabelo, E. 1921

Roeschmann, $\mathbf{H}$. 1929

Santos Filho 1991

Schwarcz, L. M. 1993

Souza, C. de 1909

Souza, L. de M. e 1993

Stepan, N. 1990

Virey, J. J. 1836

O caráter nacional brasileiro-bistória de uma ideologia

$4^{\mathbf{a}}$ ed., São Paulo, Liv. Pioneira Ed.

Breves consideraçôes acerca da origem da syphilis. Rio de Janeiro, Typ. Brasiliense de F. M. Ferreira.

'Testing for sexually transmissible diseases'. Em V. Berridge e P. Strong (orgs.), Aids, and contemporary bistory. Cambridge, Cambridge University Press.

Plagues and peoples. Nova York, Doubleday.

'A syphilis como factor de degeneração'. Gazeta Médica da Babia, ano XXXI, $\mathrm{n}^{\circ} 1$.

Corpos, prazeres e paixões: a cultura sexual no Brasil contemporâneo. Rio de Janeiro, Best Seller.

Elementos de bigiene. Rio de Janeiro, Francisco Alves. Brazil-Médico, ano VI, $\mathrm{n}^{\text {@ }} 3$ a 47.

Retrato do Brasil: ensaio sobre a tristeza brasileira. Rio de Janeiro, F. Briguiet \& Cia.

Le mal de Naples: bistoire de la syphilis. Paris, Seghers.

'Existia a syphilis na época do descobrimento?'. Anais Bras. de Dermat. e Sifilog., ano I, $\mathrm{n}^{\circ} 1$.

'Orientação actual da lucta contra a syphilis'. $2^{\circ}$ Boletim do VII Congresso Brasileiro de Medicina, do $1^{\circ}$ Congresso Sul-Americano de Dermatologia e Sifilografia etc. Rio de Janeiro, Imp. Nacional.

'A lucta contra as doenças venéreas na Allemanha em comparação com as medidas adoptadas em outros países'. Anais Bras. de Dermat. e Sifilog., ano V, $\mathrm{n}^{\mathrm{Q}} 12$.

História geral da medicina brasileira. 2 vols., São Paulo, Hucitec/Edusp.

O espetâculo das raças: cientistas, instituições e questão racial no Brasil, 1870 -1930. São Paulo, Companhia das Letras.

Da responsabilidade civil e criminal do syphilítico: publicação da Liga Paulista de Propbylaxia Moral e Sanitária. São Paulo, Typ. Hennies Irmãos.

O diabo e a Terra de Santa Cruz.

São Paulo, Companhia das Letras.

'Eugenics in Brazil, 1917-1940'. Em M. B. Adams (org.),

The wellborn science: engenics in Germany, France, Brazil and Russia. Nova York, Oxford University Press.

'Dissertação acerca da incontinência e seus perigos em relação às faculdades intellectuais e physicas'. Rio de Janeiro, Typ. Nacional. 